\title{
Ações intersetoriais para implementação de políticas públicas dirigidas às populações do campo, da floresta e das águas no Brasil
}

\author{
Inter-sector action for implementing public policies targeted to \\ rural, forest, and riverine populations in Brazil
}

\author{
Acciones intersectoriales para la implementación de políticas \\ públicas dirigidas a las poblaciones del campo, selva y \\ zonas fluviales de Brasil
}

CAMPO, FLORESTA E ÁGUAS: PRÁTICAS E SABERES EM SAÚDE. Carneiro FF, Pessoa VM, Teixeira ACA, organizadores. Brasília: Editora da UnB; 2017. 464 p. ISBN 978-85-230-1204-5.

doi: 10.1590/0102-311X00030620

O censo brasileiro realizado em 2010 indicou que $15,6 \%$ da população viviam em áreas rurais, no entanto a diversidade dessa população em termos de condições de vida, cultura, economia e acesso a direitos é um tema ainda pouco visibilizado na produção científica, sobretudo na área da saúde pública. Trata-se de populações que vivem no campo, na floresta e em ambientes aquáticos e têm forte relação com esses territórios em seus modos de vida, produção e reprodução social. São compostas de camponeses, agricultores familiares, trabalhadores rurais assalariados e temporários que residem ou não no campo, trabalhadores rurais assentados e acampados, comunidades de quilombos, populações que habitam ou usam reservas extrativistas, populações ribeirinhas, populações atingidas por barragens, outras comunidades tradicionais, dentre outros 1 .

Alguns autores destacam as iniquidades nas condições de vida e saúde da população do campo em relação à população urbana 2,3.

O livro Campo, Floresta e Águas: Prática e Saberes em Saúde foi produzido a muitas mãos, com participação dos movimentos sociais, comuni- dades e pesquisadores que se empenharam em registrar a criação do Observatório de Saúde das Populações do Campo, da Floresta e das Águas - Teia de Saberes e Práticas (OBTEIA), as lutas para a construção de uma política nacional dirigida à saúde dessas populações, e as batalhas para a garantia dos direitos que incluem existência, saúde, cultura e territórios.

Além disso, os autores do livro pretendem contribuir com as discussões sobre a saúde rural brasileira, com análises da situação de saúde dessas populações específicas e dos desafios e possibilidades de ações que profissionais e gestores do Sistema Único de Saúde (SUS) e movimentos sociais podem empreender em direção à qualidade de vida dessas populações.

O prefácio, de Boaventura de Sousa Santos, destaca o desafio de abordar um tema complexo como é o diálogo com as "realidades singulares, plurais, interculturais, que passam pela dimensão dos movimentos sociais, do ambiente, do trabalho, do modo de vida e do cuidado em saúde" (p. 21). Evoca o conceito de ecologia dos saberes como possibilidade para o diálogo entre conhecimentos, científicos e populares, viabilizando perspectivas, consensos e acordos para fortalecer as ações coletivas em busca da garantia de acesso à saúde.

O livro se apresenta dividido em quatro partes que estruturam grandes temas.

No primeiro deles, os autores apresentam um histórico das políticas de saúde para o campo no Brasil, desde a Liga Pró-Saneamento, em 1918, até a estruturação e implantação da Polí- 
tica Nacional de Saúde Integral das Populações do Campo e da Floresta, em 2011 e a inclusão da população das águas, em 2014. Vale destacar que, para orientar estratégias de enfrentamento das iniquidades e desigualdades em saúde, duas edições de Plano Operativo (2012-2015 4 e 2017 2019 5) foram elaboradas, designando responsabilidades das gestões federal, estadual e municipal. Nessa primeira parte do livro, os autores descrevem com riqueza de detalhes o processo de implementação do OBTEIA, criado em 2012: os desafios, os conceitos e metodologias que o embasaram, as vozes da população, a produção científica, a agregação de conhecimentos (incluindo os da saúde coletiva), e as lições aprendidas com essa experiência.

Os autores apresentam ainda as reflexões teóricas e metodológicas que basearam a pesquisa avaliativa sobre a implementação da política, com foco especial na produção de uma ciência emancipatória à luz do conceito de ecologia dos saberes, de Boaventura de Sousa Santos.

A segunda parte tratou de reconhecer a invisibilidade histórica das populações do campo, da floresta e das águas e de destacar as nuances do contexto social brasileiro que contribuem para a negligência de seu direito à saúde. São analisados dados secundários de sistemas de informações nacionais e uma busca de evidências científicas que ajudam a compreender o panorama das condições de saúde de tais populações. Analisam também algumas situações que acabam se tornando determinantes sociais da saúde de quem vive nesses territórios, e são desafios importantes para a garantia do acesso aos cuidados em saúde no SUS. Nessa parte, destacam-se dois temas importantes: o primeiro deles é a violência contra as mulheres rurais e os desafios da área da saúde para identificar os casos, notificar e atuar. As vivências de violência, especialmente a conjugal, foi tema identificado em estudos anteriores sobre a vida das mulheres rurais 6 . O segundo tema retrata a contribuição do Programa Mais Médicos e das unidades básicas de saúde fluviais e equipes de saúde da família ribeirinhas, salientados como avanços para ampliar o acesso a cuidados básicos em saúde para essas populações.

Na terceira parte, a implementação da política é analisada por meio das experiências locais de territórios brasileiros. Os artigos que com- põem essa parte do livro foram baseados em estudos realizados no âmbito do Observatório e descortinam os desafios territoriais, a pluralidade e a diversidade de contextos e de sujeitos. Identificam as dificuldades que enfrentam no acesso a serviços, as iniquidades em saúde, os conflitos e os impactos do processo de desenvolvimento no ambiente, a degradação ambiental, o adoecimento da população nativa e o aumento da violência. É importante exaltar a participação social e o diálogo de saberes que fica explícito durante a leitura desses artigos, mas que ainda é pouco concretizado entre gestores das políticas e as populações. Há também o debate sobre a efetiva política pública de saúde para as comunidades rurais e a necessidade de flexibilidade e adequação da política às realidades locais, garantidas nas diretrizes de territorialização e descentralização do SUS.

A quarta e última parte traz estudos de temas relacionados à população do campo, da floresta e das águas, desenvolvidos fora do âmbito do OBTEIA, mas que são essenciais quando se pensa nos modos de vida e nas questões que afetam diretamente essa população e seus territórios. Incluem análise do uso intensivo de agrotóxicos segundo cada área e culturas, as situações de risco e os impactos para a saúde dos trabalhadores; as consequências das barragens de empreendimentos hidrelétricos na vida das famílias atingidas e as lutas do Movimento dos Atingidos por Barragens pelos direitos à saúde, educação e geração de renda; e os trabalhadores, o trabalho no mangue e o conflito ambiental gerado pelo hidronegócio, descritos de forma minuciosa mediante relatos dos "povos do mangue". Por fim, o leitor encontra uma sistematização das experiências de formação de lideranças, em distintos contextos, para atuar na gestão participativa em direção à universalização do direito ao acesso à saúde no SUS.

A leitura do livro é fortemente recomendada a todos que atuam junto às populações que vivem nos territórios de campo, floresta e águas, dos mais diversos setores como gestores e profissionais do SUS, pesquisadores e alunos de pós-graduação que têm seus objetos de pesquisa ligados a esses temas e também por pessoas ligadas aos movimentos sociais que lutam pelos direitos básicos desses grupos, pois vão se identificar e se 
reconhecer como parte da produção de um conhecimento fundamental para o país.

O livro faz um importante resgate histórico das lutas pela garantia de direitos, com ênfase na saúde, pela visibilidade dessas populações na formulação, implementação e avaliação de uma política pública, e ainda demonstra na prática o diálogo profícuo promovido com base no conceito de ecologia dos saberes. Além disso, aponta caminhos baseados na construção coletiva, na qual a comunidade é tema e protagonista da sua história.

Érica Fernandes Rodrigues 1

Adalgisa Peixoto Ribeiro 1

1 Faculdade de Medicina, Universidade Federal de Minas Gerais, Belo Horizonte, Brasil.

erica-fernandes-rodrigues@hotmail.com

\section{Colaboradores}

E. F. Rodrigues e A. P. Ribeiro participaram da concepção, redação e revisão final do texto.

\section{Informações adicionais}

ORCID: Érica Fernandes Rodrigues (0000-00022332-4222); Adalgisa Peixoto Ribeiro (0000-00019415-8068).

\section{Referências}

1. Secretaria de Gestão Estratégica e Participativa, Ministério da Saúde. Política Nacional de Saúde Integral das Populações do Campo, da Floresta e das Águas. Brasília: Ministério da Saúde; 2014.

2. Rückert B, Cunha DM, Modena CM. Saberes e práticas de cuidado em saúde da população do campo: revisão integrativa da literatura. Interface (Botucatu) 2018; 22:903-14.

3. Pessoa VM, Almeida MM, Carneiro FF. Como garantir o direito à saúde para as populações do campo, da floresta e das águas no Brasil? Saúde Debate 2018, 42(n.spe 1):302-14.

4. Secretaria de Gestão Estratégica e Participativa; Ministério da Saúde. Plano operativo de saúde das populações do campo e da floresta 2012/2015. Brasília: Ministério da Saúde; 2011.

5. Secretaria de Gestão Estratégica e Participativa, Ministério da Saúde. II plano operativo de Saúde das populações do campo, da floresta e das águas 2017/2019. Brasília: Ministério da Saúde; 2017.

6. Kullok AT. A força e o vigor da mulher idosa rural: estudo etnográfico sobre envelhecimento em Dom Modesto, Caratinga-MG [Tese de Doutorado]. Rio de Janeiro: Instituto Nacional de Saúde da Mulher, da Criança e do Adolescente Fernandes Figueira, Fundação Oswaldo Cruz; 2012. 